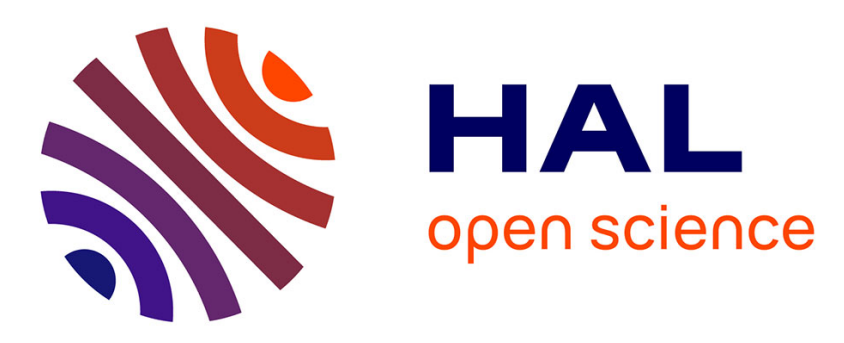

\title{
Production Capacity Pooling in Additive Manufacturing, Possibilities and Challenges
}

Siavash H. Khajavi, Jan Holmström

\section{To cite this version:}

Siavash H. Khajavi, Jan Holmström. Production Capacity Pooling in Additive Manufacturing, Possibilities and Challenges. IFIP International Conference on Advances in Production Management Systems (APMS), Sep 2017, Hamburg, Germany. pp.501-508, 10.1007/978-3-319-66923-6_59 . hal01666196

\section{HAL Id: hal-01666196 https://hal.inria.fr/hal-01666196}

Submitted on 18 Dec 2017

HAL is a multi-disciplinary open access archive for the deposit and dissemination of scientific research documents, whether they are published or not. The documents may come from teaching and research institutions in France or abroad, or from public or private research centers.
L'archive ouverte pluridisciplinaire HAL, est destinée au dépôt et à la diffusion de documents scientifiques de niveau recherche, publiés ou non, émanant des établissements d'enseignement et de recherche français ou étrangers, des laboratoires publics ou privés.

\section{(c)(1)}

Distributed under a Creative Commons Attribution| 4.0 International License 


\title{
Production Capacity Pooling in Additive Manufacturing, Possibilities and Challenges
}

\author{
Siavash H. Khajavi ${ }^{1}$ and Jan Holmström ${ }^{1}$ \\ ${ }^{1}$ Department of Industrial Engineering and Management, Aalto University, Espoo, Finland \\ \{siavash.khajavi, jan.holmstrom\}ealto.fi
}

\begin{abstract}
Industries such as aviation tend to hold large amounts of capital tied to spare parts inventories to insure a high availability [1]. One effective approach to increase the efficiency in inventory management has been resource pooling [2]. However, the emergence of additive manufacturing (AM) enables the new paradigm of production capacity pooling, which varies from current ones. AM's inherent characteristics may realize capacity sharing among distinct industries, alleviate the need for high safety stock levels and enable better customer service through the reduction of transshipments for spare parts. The advantages can be extended to the broader fulfillment reach of the firm in other geographical areas without expanding its existing production capacity or inventory (and other benefits from a distributed production setting). However, issues with inter-organizational agreements, testing and production reliability may slow down the pooling process while the required facilities are in place. This paper aims to extend the existing literature on implications of this growing phenomenon on inventory management practices. Study methodology is conceptual analysis.
\end{abstract}

Keywords: Additive manufacturing, Capacity pooling, Inventory management.

\section{$1 \quad$ Introduction}

Spare parts supply chains are profitable for the business but inherently complex and potentially wasteful. The root problem is in the stochastic and uncertain nature of spare parts demand and different service levels required to satisfy and retain customers. In industries where availability is essential and downtime is very costly; operators tend to hold a high level of safety stock on hand. For instance, according to Harrington [19] the monetary value of spare parts stock in commercial aviation industry is about 44 billion dollars. To improve the situation, researchers have utilized other technologies (such as Information and communications technology) to introduce various tools and inventory management strategies. Among those, inventory pooling strategy $[25,26]$ which is based on the resource sharing has been effective on various implementation levels (intra/ inter organizational). However, the difficulties regarding the cost sharing in inventory pooling has led to limited use of this method to reduce the costs for instance among the airlines [2]. 
Currently, digitalization of manufacturing enabled by additive manufacturing (AM) methods has the potential to affect a major improvement throughout supply chains [5, $6,24]$. Therefore, a detailed impact investigation of this phenomenon on current supply chain practices will provide a better understanding among the managers in this field. Hence enabling them to make more informed decisions and take advantage of the possibilities while staying away from the possible threats.

The paper is structured in five sections; Introduction, literature review on resource pooling and additive manufacturing, Methodology, Results and Conclusions. Capacity pooling in this research refers to the pooling of the production capacity.

\section{Description of Basic Concepts}

\subsection{Resource Pooling}

According to $\mathrm{Yu}$ et al. [11], "capacity pooling refers to the consolidation of capacity that resides in multiple facilities into one. In a system without pooling, each facility fulfills its own demand relying solely on its capacity." Inventory pooling is described in same manner by Wong et al. [20] as "inter-company cooperation where the cooperating companies share their inventories, is an effective strategy to improve a company's logistical performance without requiring any additional cost. Cooperation usually takes the form of lateral transshipments (LT) from a location with a surplus of on-hand inventory to a location that faces a stock-out". As understood from Yu et al. description, pooling of resources including inventory may also be implemented in an intra-organizational setting, where a company reduces its variety of products (e.g. iPhone which works both for AT\&T and Verizon) or centralizes its warehousing to reduce its safety stock (cost) and simultaneously improve its response time (however, according to literature the simultaneous cost cutting and improved response time is not always the case). Introduction of a centralized location imposes the additional transportation in case of inventory pooling which might increase the response time [15].

The literature on the subject of inventory and capacity pooling is extensive. Since Eppen [13] introduced benefits of a centralized inventory pool, the body of knowledge around it expanded ever since. Various papers are dedicated on solving the issues regarding the cost sharing in inter-organizational context while others studied the potential benefits of inventory and capacity pooling in different demand settings and demand correlations impact the pooling outcome [17]. Moreover, studies have been conducted to enable the airlines to take advantage of this concept and reduce their inventory costs [2]. A comprehensive review of literature regarding the capacity and inventory pooling is presented in Yu et al. [11] work.

Reviewing the literature regarding the benefits of pooling policies in operations management, suggests that gained benefits are improved customer response time, reduction in total system cost (reduced safety stock and lower overheads) and simplification of inventory control and production process $[13,15]$.

Among the companies which have implemented resource (inventory or production capacity) pooling, we can refer to KLM, SAS, Swissair, UTA (as KSSU consortium) 
and Air France, Alitalia, Iberia and Lufthansa (as Atlas consortium) in commercial aviation industry; Amazon, Google intra-organizational cloud services, Fujitsu and AMD flash memory production, Acer, IBM, Compaq assembling their computers in same plant in 1990's; Isuzu, General Motors diesel engine plant. Moreover, organizations such as hospitals and public sector also take advantage of resource pooling in their operations [2,14].

Resource pooling in an inter-organizational setting is rather more challenging because of two reasons. First, all parties attending the pool should benefit in a balanced manner from their participation; otherwise taking part in the pool will not be rational [28]. Competitive behavior of pool partners will likely derail this effort. Second, cost sharing in a pool needs to be sorted out through an initial agreement to keep the pool functioning [1]. For instance, literature suggests that sizable airlines tend to keep their own inventory management operations and not taking part in spare parts inventory pools consisting of smaller companies [2].

\subsection{Additive Manufacturing}

A growing branch of direct digital manufacturing technologies which implements layers deposition or solidification technics to objectify theoretically any intended item. AM is increasingly being used as final parts production system [24]. Currently, main obstacles for a wider industrial implementation are related to limitations in the range of raw material availability, production phase, product finish and physical size limitations (especially for the metal AM). On the other hand, AM offers several unique features which are the forces behind its growth. According to Holmström et al., [5] geometrical complexities are not costlier to produce nor difficult, which means enabling design for performance concept (is highly valuable for industries such as aerospace that extra weight equals extra lifecycle costs). In AM, the economies of scale does not hold as there is no need for tooling therefore producing individually customized parts is not more resource intensive than producing batches of standard parts (the main cost drivers while calculating the parts' value are time and material expenditure).

\subsection{Literature Gap}

There exist various studies which explore the benefits and limitations of production capacity pooling. Jain [10] studied the impact of varieties of demand on the value of capacity pooling. Benjaafar et al. [12] investigated the differences between benefits of capacity pooling and inventory pooling.

Holmström et al. [5] in their study, briefly pointed out the benefits and shortcomings of capacity pooling while AM is implemented. The fact that AM capacity is not limited to specific use and might be utilized to produce any part if the material requirements are matched is pointed out. Moreover, concerns regarding the quality of produced parts and availability of pooled capacity when is needed, has been discussed. Khajavi et al. [6], provides an example of distributed AM implementation and illustrates the feasibility of high excess capacity in that setting. In this work, we investigate this matter more in-depth. Answering the following research questions will help us fulfill this goal. "What are the advantages and limitations of AM production capacity pooling?" 


\section{$3 \quad$ Methodology}

The methodology chosen for this research is conceptual and theoretical analysis through the study of similar phenomenon in other industries [23]. We chose airlines industry and cloud computing as two of the fields where practice of capacity pooling has been implemented before. The main sources of our data are secondary data in the form of journal articles, books and websites which provide relevant material on inventory pooling practices as well as production capacity pooling instances and AM. The search keywords that used to find the research material in the library and internet data bases are as follows; Inventory pooling, capacity pooling, production capacity pooling, pooling benefits, AM pooling, rapid manufacturing pooling.

The main reason for the selection of conceptual and theoretical methodology is the current lack of empirical case data in this specific field. This is due to the position of AM at early stages of its lifecycle as a functional parts production technology.

\section{$4 \quad$ Advantages and Limitations of AM Capacity Pooling}

\subsection{AM capacity pool types}

An AM enabled capacity sharing may take place as companies with implemented machines starting to share their unused capacity under different types of agreement. Or it might take place as an OEM or A third party service provider configures a network of $3 \mathrm{D}$ printing machines to provide production capacity as a service [5]. The former concept is similar to peer to peer (P2P) network concept which users utilize their peers' excess bandwidth for sharing data among each other without utilizing servers as their connection nodes [29]. On the other hand, the latter concept of AM capacity sharing is comparable to Amazon company business model of providing cloud services (computing, storage and bandwidth) to many customers through its pool of datacenters.

In $\mathrm{P} 2 \mathrm{P}$ capacity pooling, companies with excess AM production capacity, tend to participate in the pooling network if they get compensated for that or they require more capacity in geographical locations which other members are present in [6]. Moreover, the size and reach of a company will potentially be effective in inter-organizational agreements. In this scenario, as for the inventory pooling in airline industry, the biggest players tend to acquire or construct their own networked capacity pool and not get involved into pooling arrangements with smaller players [2,27] (e.g.: GE aviation acquisition of Morris technologies and Rapid Quality manufacturing AM facilities [24]).

In a third-party capacity provision setting, each client company might be active in a different industry and a distinct geographical location which makes it difficult for the service provider to establish a centralized production facility trying to serve all the locations from there. Thus, it can take advantage of production distribution [5] and locate the AM machines in optimal proximities to customers' facilities in order to be profitable and provide high service levels, quicker [6]. This strategy requires the firm to be agile and reconfigure its network or add new machines to the network while adding new clients. 


\subsection{Higher flexibility}

In general, one of the advantages of AM capacity pooling over inventory pooling is flexibility of use. Meaning that, it can be dedicated to produce any part as long as the material and quality requirements of machines and parts are matched [21]. In traditional inventory pooling companies tend to share their excessive resources including the fast or slow-moving parts. Hence inventory pooling is just limited to surplus units in same industries and often exact same stock keeping units (SKUs). However, in an AM enabled capacity pooling scenario, not only companies in different industries can cooperate to form the pool, also the need for companies to hold high safety stock levels for slow moving parts will vanish. This means that companies will be able to take advantage of postponement strategy by delaying the production of required parts until there is a need for them [22]. In the latter strategy, capacity pool reduces spare parts inventory carrying cost while increasing raw material holding, possible post production process and testing expenses.

In an AM enabled spare parts supply chain for F-18 Super Hornet airplanes, simulation showed while current AM machines are not ideal for a distributed production, future developments might trigger cost efficiency with high level of spare capacity in decentralized setting. In F-18 aircraft case, centralized production of spare parts yielded about 5\% excess capacity while the distributed production resulted in excess capacity of 75\% [6]. The numbers are large and illustrate how local manufacturing of parts save time and consequently cost in an aerospace spare parts provision, while at the same time resulting in a buffer available for pooling.

\subsection{Reduced transportation}

Another advantage of this technology which was concisely discussed, is the reduced necessity for transshipments [5]. In contrast to a centralized inventory capacity, this strategy is more similar to virtually centralized inventory pool but with obvious advantages. In a virtual inventory if the part does not exist at the inventory branch near the market there is a need for transshipment of the part from the other closest branch which possesses the part [16]. However, in AM capacity pool, this transshipment will not exist if all of the parts and machines are compatible and the pool (among peers or provided by third party) is located in various geographical locations close to markets [6]. This may translate to independent operation of each network node and higher focus on local responsiveness.

\subsection{Division of cost}

Cost allocation strategy is an important matter which needs to be aligned before the implementation of a pooling policy [1]. Obviously, all parties involved in the pool intend to alleviate their inventory costs lower than the scenario in which they solely manage their inventories. However, existence of competitive or cooperative tactics leads to different outcomes. Situations which a company puts its own interests on higher priority at the expense of others [3]; or in cooperative scenarios that all of the companies tend to reduce their costs to a lower level than their individual operation levels, while also 
keeping the other players cost reduction intentions in-check [4]. These characteristics in a pooling scheme bring up two major types of inventory pooling decision making polices: centralized and decentralized. In AM capacity pool, a decentralized decision making on cost allocation might prove to be more effective as each node of the network is more accurately possesses its production schedule [9]. The cost sharing for AM capacity also might be based on machines' production hours and consumed raw materials [18]. A pooled capacity might happen to be one slot among a number of parts produced at once in a production chamber.

\subsection{Matching material, process, skill}

AM advantages come with its costs and limitations. The availability of exact same material and production process as well as testing requirements (which were briefly discussed before) are among the obvious issues [18]. For instance, since there exist various AM production methods, and each method differs from others in the utilized raw material and output properties [21], therefore, pool should possess a balanced number and types of machines as well as inventory of required materials. Moreover, for the testing process, suitable machinery or skilled workforce might become a bottleneck.

\subsection{Intellectual property rights}

Another concern over AM capacity pooling comes from intellectual property rights aspect. While acquiring parts from a capacity pool of an original equipment manufacturer (OEM) might not touch on this subject, spare parts production through third party AM providers or P2P networks is more complex. The IPR and reliability complexities is related to an OEM reluctance to provide the customers with the products' spare parts digital blue prints [27] or the warranty and also realization of liable party in case of part or system failure. From this perspective AM enabled capacity pooling is more difficult to establish than inventory pools. One obvious solution might emerge from OEMs licensing third party service providers and simplify the process for the customer.

\section{Conclusions}

As AM is slowly gaining foothold as a final parts production method, illustration of its potential managerial implication becomes essential. In this research, we compared the traditional inventory and capacity pooling benefits and limitations to an AM enabled capacity pooling in spare parts provision context. The traditional pooling has proved to be effective in improving companies' efficiencies in many cases. Reducing safety stock which leads to lower costs and commonly (but not always) improved service levels has been observed by the researchers as the positive benefits of pooling strategies. However, one of the important challenges realized to be cost sharing strategies among pool members. In this article which is a conceptual paper based on literature case reviews, we described peer to peer type AM capacity pooling and third-party pools and illustrate their differences. Consequently, the major advantages of AM pooling were explained. 
Flexibility of AM capacity which enables production pools among companies in different industries as the parts are not limited by forms long as the print is not started. In a distributed AM capacity pool, this will lead to reduced transshipments and safety stock for slow moving parts. On the other hand, the need for raw material inventories, material and process matching, post production activities and IPR complexities are the most important challenges in front of AM capacity pooling.

This is important to be pointed out that, AM currently is most suitable while the parts are small and have complex geometries and also needed to be produced in limited production batches. The production configuration of choice is centralized since machines are expensive, labor intensive and provide rather low production rates. However, the potential for a distributed AM production systems in the future is irrefutable. Hence this study provides the stepping stone for the research in AM distributed production configuration to prepare managers for probable changes.

This article's limitations have their roots in the discussed facts regarding the lack or handful number of available cases in AM final products implementations; however, we utilized the literature to close the gap to the reality. For future research, cost analysis comparing AM enabled capacity pooling to inventory pooling, empirical study of the findings and also IPR strategizing in AM pooling context are worthwhile topics. Moreover, as an arena for the future research we also propose four scenarios to be compared with one another in an empirical setting which are as follows: Inventory pooling managed by participants (Base case scenario 1), inventory pooling managed by third party (Scenario 2), capacity pooling by the participants (Scenario 3 ) and third party managed capacity pool (Scenario 4).

\section{References}

1. Wong, H., Oudheusden, D. V., \& Cattrysse, D. (2007). Cost allocation in spare parts inventory pooling. Transportation Research Part E: Logistics and Transportation Review, 43(4), 370-386.

2. Kilpi, J., \& Vepsäläinen, A. P. (2004). Pooling of spare components between airlines. Journal of Air Transport Management, 10(2), 137-146.

3. Kogut, B. (1989). The stability of joint ventures: Reciprocity and competitive rivalry. The Journal of Industrial Economics, 183-198.

4. Özen, U., Fransoo, J., Norde, H., \& Slikker, M. (2008). Cooperation between multiple newsvendors with warehouses. Manufacturing \& Service Operations Management, 10(2), 311-324.

5. Holmström, J., Partanen, J., Tuomi, J., \& Walter, M. (2010). Rapid manufacturing in the spare parts supply chain: alternative approaches to capacity deployment. Journal of Manufacturing Technology Management, 21(6), 687-697.

6. Khajavi, S. H., Partanen, J., \& Holmström, J. (2014). Additive manufacturing in the spare parts supply chain. Computers in Industry, 65(1), 50-63.

7. Ruffo, M., Tuck, C., \& Hague, R. (2006). Cost estimation for rapid manufacturing-laser sintering production for low to medium volumes.Proceedings of the Institution of Mechanical Engineers, Part B: Journal of Engineering Manufacture, 220(9), 1417-1427. 
8. Kilpi, J., Töyli, J., \& Vepsäläinen, A. (2009). Cooperative strategies for the availability service of repairable aircraft components. International Journal of Production Economics, 117(2), 360-370.

9. Gunasekaran, A. (1999). Agile manufacturing: a framework for research and development. International journal of production economics, 62(1), 87-105.

10. Jain, A. (2007). Value of capacity pooling in supply chains with heterogeneous customers. European Journal of Operational Research, 177(1), 239-260.

11. Yu, Y., Benjaafar, S., \& Gerchak, Y. (2006). On service capacity pooling and cost sharing among independent firms. Working Paper, Department of Mechanical Engineering, University of Minnesota.

12. Benjaafar, S., Cooper, W. L., \& Kim, J. S. (2005). On the benefits of pooling in productioninventory systems. Management Science, 51(4), 548-565.

13. Eppen, G. D. (1979). Effects of centralization on expected costs in a multi-location newsboy problem. Management Sci. 25 498-501.

14. Yu, Y., Benjaafar, S., \& Gerchak, Y. (2008). Capacity pooling and cost sharing among independent firms in the presence of congestion. Under Review.

15. Kim, J. S., \& Benjaafar, S. (2002). On the benefits of inventory-pooling in production-inventory systems. Manufacturing \& Service Operations Management, 4(1), 12-16.

16. Wong, H., van Houtum, G. J., Cattrysse, D., \& Oudheusden, D. V. (2006). Multi-item spare parts systems with lateral transshipments and waiting time constraints. European Journal of Operational Research, 171(3), 1071-1093.

17. Corbett, C. J., \& Rajaram, K. (2011). Aggregation of uncertainty and multivariate dependence: The value of pooling of inventories under non-normal dependent demand.

18. Gibson, I., Rosen, D. W., \& Stucker, B. (2010). Additive manufacturing technologies (pp. 1-8). New York: Springer.

19. Harrington, L. (2007). From just in case to just in time. ATW: Air Transport World, 44(4).

20. Wong, H., Cattrysse, D., \& Van Oudheusden, D. (2005). Inventory pooling of repairable spare parts with non-zero lateral transshipment time and delayed lateral transshipments. European Journal of Operational Research, 165(1), 207-218.

21. Hopkinson, N., Hague, R., \& Dickens, P. (Eds.). (2006). Rapid manufacturing: an industrial revolution for the digital age. John Wiley \& Sons.

22. Alderson, W. (2006). Marketing efficiency and the principle of postponement. InA TwentyFirst Century Guide to Aldersonian Marketing Thought (pp. 109-113). Springer US.

23. Webster, J., \& Watson, R. T. (2002). Analyzing the past to prepare. MIS quarterly, 26(2), 13-23.

24. GE Aviation, (2012). GE Aviation acquires Morris Technologies and Rapid Quality Manufacturing. http://www.geaviation.com/press/other/other_20121120.html

25. Simchi-Levi, D. (2009). Designing and managing the supply chain concepts strategies and case studies. Tata McGraw-Hill Education.

26. Lee, H. L. (2002). Aligning Supply Chain Strategies with Product Uncertainties. California management review, 44(3).

27. Michael Gubisch, (2012), MRO consolidation leads to different airline supplier environment, http://www.flightglobal.com/news/articles/in-focus-mro-consolidation-leads-to-different-airline-supplier-377969/

28. Naesens, K., Gelders, L., \& Pintelon, L. (2007). A swift response tool for measuring the strategic fit for resource pooling: a case study. management Decision, 45(3), 434-449.

29. Schollmeier, R. (2001, August). A definition of peer-to-peer networking for the classification of peer-to-peer architectures and applications. In Peer-to-Peer Computing, 2001. Proceedings. First International Conference on (pp. 101-102). IEEE. 